\title{
Fair Weather Voters: Do Canadians stay at home when the weather is bad?
}

\author{
Authors: Daniel Stockemer ${ }^{1}$, Michael J. Wigginton ${ }^{2}$
}

Affiliations: ${ }^{1}$ School of Political Studies, University of Ottawa, Room FSS7005, 120 University Private, Ottawa ON K1N 6N5, email: daniel.stockemer@uottawa.ca

${ }^{2}$ School of Political Studies, University of Ottawa, Room FSS7005, 120 University Private, Ottawa ON K1N 6N5, email: michael.wigginton@uottawa.ca

This is a post-peer-review, pre-copyedit version of an article published in the International Journal of Biometeorology. The final authenticated version is available online at: https://doi.org/10.1007/s00484-018-1506-6.

Please do not cite this version.

Date: February 2018

Abstract: What is the relationship between precipitation and the temperature on turnout? Using data on the 2004, 2006, 2008, 2011, and 2015 Canadian federal elections, we try to answer this question. Through bivariate and multi-variate statistics, we find that each millimeter of precipitation decreases turnout by more than .1 percentage points. When it comes to the temperature our results indicate that higher temperatures trigger higher turnout. However, we also find that these relationships are influenced by season, and only apply to spring, summer and fall elections. In the winter 2006 elections, the association was inversed; warmer temperatures in this election triggered lower turnout, in particular when it was combined with precipitation.

Key words: precipitation, temperature, weather, turnout, Canada 


\section{Introduction}

Does bad weather in the form of rain, snow and low temperatures prevent citizens from voting on Election Day? Utilizing a rational choice perspective, two scenarios are possible: on the one hand, unpleasant weather may dissuade citizens from voting by increasing the costs associated with going to the polls. In rainy, snowy or cold weather it is unpleasant to leave one's home and citizens might try to avoid getting wet or cold while standing in line at or traveling to the polls. On the other hand, particularly pleasant weather could also deter voters by increasing opportunity costs, as voting may interfere with the enjoyment of a nice day either at the beach, in the mountains, or just in one's garden. If either, which of the two perspectives holds? In this article, we address this question by focusing on five Canadian legislative elections (i.e. the general elections of 2004, 2006, 2008, 2011 and 2015) ${ }^{1}$. Specifically, we test the influence of two weather-related factors (the amount of precipitation and the temperature) on voter turnout. We expect that more citizens will participate in elections in warm and dry weather.

Our dependent variable is the percentage of registered voters in Canada that cast their ballot, measured at the level of the electoral district. Our independent variables are the amount of precipitation on Election Day measured in millimeters and the temperature measured in Celsius. Controlling for each district's median age and income, number of polling stations, population density, the percentage of residents who are immigrants, the electoral competitiveness, as well as for northern districts, we find that both weather related proxies generally influence turnout. The former of the two measures, precipitation, decreases turnout, while the latter, higher temperatures, increases turnout.

This article proceeds as follows: first, we will succinctly summarize the previous literature on weather related factors and turnout, as well as formulate our hypotheses. Second, we will present the data, case, and control variables. In the third part, we will quickly describe the statistical procedures employed in our analysis. Then, we will present and discuss the results of our quantitative study. Finally, we will situate our study within the current literature and provide some avenues for future research.

\section{Weather and the turnout literature}

The turnout literature is one of the largest and most developed literatures in the field of political behavior (Blais 2006). There are two strands of turnout studies: first, individual-level studies which try to decipher which personal characteristics render one citizen more likely to vote than another. In general, the one's likelihood of voting increases with age, education, income, and political interest and knowledge (Smets and van Ham 2013). Second, macro-level analysis try to determine how the context in which the election takes place influences turnout. These studies concur that turnout generally increases under compulsory voting, under proportional representation in large districts, and when the elections are important and decisive or close (Geys

\footnotetext{
${ }^{1}$ Although desirable, including additional elections prior to 2004 was not feasible as Canada underwent major redistricting prior to the 2004 elections.
} 
2006; Stockemer 2017). Aside from these institutional factors, there is some, albeit inconclusive, support that the composition of the district (e.g. urban versus rural, ethnic composition, and level of affluence) as well as corruption and income inequality hamper turnout (Stockemer et al. 2013).

In this study, we examine another macro-level factor, the weather, and its influence on turnout. There are two types of studies examining how weather or climate related factors can influence turnout: one array of studies looks at seasonal effects, and the second at the precise weather on Election Day. When it comes to studies looking at seasonal effects, there is some evidence that elections conducted in the winter months trigger lower turnout than elections conducted in the spring, and moderately lower turnout than elections held in the summer and fall. For example, LeDuc and Pammett (2006, p. 307) highlight that Canadian elections held in the winter had, on average, 6 percentage points lower turnout than elections conducted in the spring (67.7\% versus $74.4 \%$ ). Studlar (2001) confirms this finding; according to his analysis, spring elections consistently had the highest turnout since 1940 in Canadian federal elections (for a similar result for local elections in the United Kingdom, see Rallings et al. 2003).

When it comes to the causal mechanisms behind the finding that spring is the season that triggers the highest turnout, there is some evidence that the length of daylight plays a role in voters' decision to turn out. For example, Rallings et al. (2003) posit that the longer the daylength the higher the turnout, as voters may be more reluctant to vote on darker days. Eisinga et al. (2012b) contextualize this finding and report that each additional hour of daylight corresponds to approximately a one-half percentage point increase in turnout. For a different seasonal factor, research has shown that seasonal holidays may put a drain on turnout, as well, because voters might have planned free-time activities such as vacationing or visiting friends out of town during the holiday. To support this conjecture, Dubois and Lakhdar (2007) report that turnout in French Presidential Elections is approximately 1.7 percentage points lower in departments that are experiencing school holidays compared to departments with no school holidays. ${ }^{2}$

When it comes to studies looking at the influence of the weather on Election Day on political behavior, earlier studies (e.g. Ludlum 1989) have speculated for quite some time that poor weather such as low temperatures and precipitation, deter citizens from going out to vote. This speculation has been echoed by electoral bodies. For example, the Nova Scotia House of Assembly asserted in a 2009 report that poor weather and icy roads deter citizens from voting, though they cited no evidence to support this claim. The academic literature empirically supports these claims, but only finds a fairly minor drop in turnout triggered by poor weather. For example, Artés (2014) finds in the case of Spanish elections that a one millimeter increase of rainfall results in a turnout decrease of 0.053 percentage points. For the United States 1982 general elections, Merrifeld (1993) reports that per each millimeter of rainfall in a region, turnout decreases by .015 percentage points. Fifteen years later, Gomez et al. (2007) report a slightly

\footnotetext{
${ }^{2}$ In the Canadian context, a similar negative effect is often found during winter elections for so-called 'snowbirds' who spend the winter outside of Canada in warmer climates. For them, postal voting might be too difficult and costly. (Elections Canada, 2006, p. 8; LeDuc \& Pammett, 2006)
} 
higher decrease; in their study on the US, the reported turnout decrease is 0.035 percentage points per millimetre increase in rainfall. Very similarly, and using the Netherlands, as a case, Eisinga et al. (2012b) find that per each millimetre of rainfall turnout decreases by 0.041 percentage points in the Dutch parliamentary elections. A contrary finding applies for the Norwegian municipal elections, where increased rainfall is actually associated with increases in turnout (Lind, 2014). ${ }^{3}$

Arnold, (forthcoming, p. 22) reports some more nuanced findings. Focusing on the Bavarian mayoral elections, his first finding is that the absence of rain is associated with a slight decrease in turnout, though substantial rainfalls also have a slight turnout-depressing effect. Arnold also reports that the depressing effect of rain on turnout is lessened in more competitive Bavarian mayoral elections. He argues that voters' perception that their vote can potentially have a great impact on the election outcome lessens the importance of costs such as rain. Fraga and Hersh (2010) observe similar results in US presidential elections, where precipitation only has an impact on turnout in uncompetitive elections. One of the few studies which finds no significant effect is Persson et al. (2014), who evaluate the effect of rainfall on turnout using both individual- and aggregate-level data in Swedish parliamentary elections; regardless of the data they use, the authors find no significant and robust effect between the two variables. ${ }^{4}$

There are also some, albeit few, studies, which discuss the type of individuals that might be enticed to stay at home due to rain. For example, Knack (1994) highlights that rain only depresses turnout for citizens with a low sense of civic duty, leading him to conclude that only 'peripheral' voters are deterred. Bassi's (2013) more psychological study suggests that poor weather influences the mood of some voters, and can impact their vote choice. While this laboratory study did not address abstention directly, we deem it likely that some citizens may conceivably experience a similar psychological effect; that is, the mood change induced by the weather may entice them to stay home rather than turn out on Election Day. ${ }^{5}$

As second measure of the Election Day weather, the role of temperature in determining electoral turnout has been far less studied than that of precipitation. We only know of four studies: (1) Artéz's (2014) study of Spanish elections includes temperature data, but finds no

\footnotetext{
${ }^{3}$ A slightly different type of analysis, distinguishes between two forms of precipitation, rainfall and snowfall and their influence on turnout. For example, two US studies, by Gomez et al. (2007) and Fraga and Hersh (2010) find that rain has a stronger negative effect on voting than snowfall, despite its overall moderate influence.

${ }^{4}$ In addition, several studies have focused on the partisan electoral implications of weather-related turnout decreases. In the majority, these studies concur that conservative parties benefit from this turnout decline. For example, Gomez et al. (2007) report that in US presidential elections every inch of rain above the election day normal results in a $2.5 \%$ increase in the Republican vote share $(0.098 \%$ per $1 \mathrm{~mm}$ increase). Gatrell and Bierly confirm these results for the 2012 general election in the State of Kentucky. Similarly, Eisinga, et al (2012a) find that right-leaning parties benefit from inclement weather; if the weather is bad, each right leaning party gains one seat in the Dutch parliament, whereas, left-leaning parties lose approximately one seat. Arnold and Freier (2016) highlight that in German local and state elections, rain-related turnout decreases also benefit the success of the conservative CDU, at the expense of the more left-wing SPD. Finally, Artés (2014) confirms that turnout increases due to dry and pleasant weather hurt the vote share of the Spanish conservatives, primarily to the benefit of small left-wing parties.

${ }^{5}$ The studies, we cite here, measuring the influence of precipitation on turnout, normally do not control for temperature.
} 
significant effect on turnout. (2) Eisinga et al. (2012b) do find significant effects from temperature on Dutch election turnout, estimating a modest increase of 0.119 percentage points per degree Celsius of temperature increase. (3) Focusing on French parliamentary elections, Ben Lakhdar and Dubois (2006) examine the effect of temperature on turnout in terms of the difference from the average temperature for the area, finding a one-point increase in turnout for a $3^{\circ} \mathrm{C}$ increase above the average normal temperature. Finally (4), Matsusaka and Palda, (1999) incorporate temperature data in their study on turnout in the 1980 US federal elections; they conclude that temperature does not affect citizens' likelihood to cast their ballot. ${ }^{6}$

To sum up, the majority of studies looking at the influence of rainfall on turnout find a small negative influence of precipitation on turnout. However, this finding is not conclusive and possibly conditional to certain conditions on the ground (see Fraga and Hersh 2010; Persson et al. 2014). Many existing studies also have some inherent methodological weaknesses. They are conducted in relatively small geographic areas and thus capture a limited range of climatic variation. Furthermore, some research examines only a single election, and most studies are conducted in systems with unvarying election dates (e.g. US presidential elections are always in November, Norwegian municipal elections in September, etc.). This focus on one electoral cycle or date might mask the possibility that the relationship between precipitation and turnout might be different based on the season. For example, warmer temperatures might be beneficial for increased participation in winter, while in the summer the reverse might be true. When it is 30 degrees Celsius, voters might either deem it too hot to leave their home or prefer other uses of their free time, such as swimming. This possible variation in the relationship between weather and turnout becomes more important given that the few existing studies - particularly in the temperature turnout realm - provide inconclusive results. In addition, no study has examined if the effect of precipitation and the temperature on turnout is similar in the winter, spring, summer and fall periods. Therefore, it is important to engage in a renewed analysis of the relationship between precipitation and temperature as the right-hand side variables in regression equations and turnout as a left-hand side variable. We do so using district level data for five Canadian elections (i.e. the 2004, 2006, 2008, 2011, and 2015 general elections). Three considerations inform this choice: (1) the size of the country, (2) the fact that elections are held at varying times of the year and (3) that there are a lot of public discussions of the possible relationship between the weather and turnout in Canada.

First, thanks to its size and the various weather patterns in various parts of the country Canada is geographically well-suited for this analysis. It provides enough variation on the independent variables, the temperature and the amount of precipitation. For any election between 2004 and 2015, the amount of precipitation covered fluctuated between 0 and 15 millimeters of rainfall and for some elections between 0 and 30 millimeters. The temperature difference between electoral districts was over 15 degrees for the 2004 elections and over 20 degrees for other elections. We can find the same variation in the dependent variable turnout, which

\footnotetext{
${ }^{6}$ Matsusaka and Palda (1999) also report that rainfall does not influence electoral participation in their study.
} 
fluctuated by more than 30 percentage points between electoral districts in any of the five election years.

Second, Canada is one of the few countries which holds elections in irregular intervals. Following the British Westminster model, the Canadian Prime Minister can ask the GovernorGeneral to call an election any day within a five-year framework from the previous election. ${ }^{7}$ Contrary to most countries like the US or France, this means that elections can and do happen in different seasons. For example, the five elections we cover in this study took place in all four seasons. In more detail, our data cover the winter elections in 2006 (i.e. January 23, 2006), the spring elections in 2011 (i.e. May 2, 2011), the summer elections in 2004 (i.e. June 23, 2004) and the two fall elections in 2008 and 2015 (i.e. October 14, 2008 and October 19, 2015).

Third, the role of the weather in influencing elections has been a matter of public discussion in Canada over the past decades. In particular, the expected cold temperatures in the January 2006 federal elections, the first federal elections to be held during winter in over 25 years, became a topic of public discussion. Commentators on the radio and on TV affirmed loud and strong that this election timing would drive turnout even further below the historic low of $60.5 \%$ achieved in 2004 . However, in reality turnout rose to $64.9 \%$, possibly as a result of increased voter awareness campaigns and the unseasonably pleasant temperatures on Election Day (LeDuc and Pammett, 2006; Elections Canada, 2006, p. 8). Even beyond the 2006 elections, the weather-turnout nexus has remained important in the Canadian context. Statistics Canada even included the weather as a possible reason for non-voting in the 2011 Labour Force Survey. The survey data reveal that voters do not seem to make a conscious decision to stay home due to inclement weather - when asked about the reasons for their abstention, only $0.1 \%$ of non-voters cited poor weather as their main reason for not casting a ballot, with the majority citing a lack of either interest (27.7\%) or time (22.9\%) (Statistics Canada, 2012).

Are voters' self-assessments confirmed in district level macro-level data? Does bad weather depress turnout? Building on most previous research we think it does and expect the following: (1) the higher the amount of precipitation the lower the district level turnout, and (2) the higher the temperature the higher the district level turnout. We are also interested if these relationships hold across spring, summer, fall and winter elections, or if different dynamics are at play in different seasons. We test our expectations based on data for almost all electoral districts in Canada for the 2004 to 2015 elections. ${ }^{8,9}$ In the next section, we present the variables and data.

\footnotetext{
${ }^{7}$ Officially, Canada has had fixed election dates since 2007, with elections occurring on the third Monday in October. In practice, this rule was not followed either in 2008 or 2011. Although this law increases pressure to hold elections at regular intervals, to date only the 2015 election was held on the prescribed date, and the instability of minority governments makes early elections possible and even likely in the federal elections to come.

${ }^{8}$ We excluded Canada's three artic territories from the analysis. Additionally, we excluded the electoral district of Durham for the year 2004 due to the unavailability of census data.

${ }^{9}$ Before the 2015 election, federal electoral districts underwent regular decennial redistricting that moved some electoral boundaries and created 30 new ridings. To account for this, our pooled models include only those 2015 districts which lost no more than $40 \%$ of their territory in the redistricting, and gained no more that $40 \%$ new
} 


\section{Variables and Data}

The dependent variable is the official turnout statistic for each electoral district; it measures the percentage of registered voters that cast their ballot during the respective federal election. ${ }^{10}$ The data come from Elections Canada's official turnout results, which are published following each federal general election (Elections Canada, 2017). Our two weather-related proxies or independent variables, measure the amount of precipitation in millimeters and the average daily temperature in degrees centigrade in each electoral district. The data for our weather proxies come from Environment Canada's historical data service, which provides historical meteorological readings from weather stations across the country (Environment and Climate Change Canada, 2017). In larger electoral districts with multiple available weather stations, we used the weather station for the riding's largest population centre (e.g. for Central Nova which includes multiple municipalities, we took weather data for the town of New Glasgow). In more concentrated urban areas with multiple electoral districts in the same municipality, we sometimes had to use the same weather station for multiple ridings (e.g. all downtown Toronto districts shared the same weather data). In total, we used 135 weather stations with slight year-to-year variations as stations became disused or new stations appeared.

Since the weather is likely not the only variable which influences district level turnout, we control for seven likely predictors of turnout, all at the district level; median age and income, population density, the percentage of immigrants, the number of polling stations, and the northern location of the districts. We sourced the first five of these predictors from Statistics Canada's 2006 and 2011 Censuses of Population, ${ }^{11}$ as well as the National Household Survey of $2011^{12}$. We collected the sixth control variable, the number of polling stations per district from the Elections Canada data (Elections Canada, 2017).

When it comes to our control variables, we first hypothesize that districts with older electorates should have higher turnout. Research (e.g. Franklin 2004; Melo and Stockemer 2014) has established that voting is more of a habit for older individuals than for younger people. Normally, the older citizens are, the more civic minded they are, the more integrated they are in society, and the more stable political ideologies they have, all of which should contribute to a higher likelihood to vote. In this study, we further assume that what applies to the micro-level should also apply to the macro-level; that is older electorates should trigger higher turnout. We operationalize age by the median age in the electoral district.

\footnotetext{
territory, as calculated by the Pundit's Guide to Canadian Elections (Funke, 2017). In total, we matched 93\% of the 2004-2011 districts to a 2015 district.

${ }^{10} \mathrm{We}$ used electoral districts instead of polling sub-divisions as census data were unavailable for theses smaller areas. The same applies to more precise weather data.

${ }^{11}$ Ideally, we would have liked to use the 2016 census for the 2015 election, however not all the necessary data had been released at the time of data collection.

12 Stephen Harper's Conservative government abolished the mandatory long-form census, replacing it with the optional National Household Survey, which collected the same information. The mandatory short-form census did continue to exist for more basic demographic data, and was used for population and age data in our sample.
} 
We use a similar logic for the second control variable, the average income per district; that is on the micro-level it is an established finding that individuals' likelihood to vote increases with their socio-economic status (SES) (Gallego 2010). In other words, individuals in the higher echelons of society have the personal and financial resources to get politically engaged, as well as the network connections (Verba et al. 1995). As it is standard in the literature, we measure somebody's SES by their income. Because we have an aggregated analysis, we use the median individual income per district.

The third control variable gauges the degree of urbanization in a district. Because of higher levels of religiosity and closer links between politicians and parties, among other things, turnout has traditionally been higher in the countryside than in cities and urban hubs in Canada and other Western countries (Corvalan and Cox 2013; Smets and van Ham 2013). We have no reason to assume that this relationship should not hold for our study. Hence, we hypothesize that more rural districts should have higher turnout than more urban districts. We measure the degree of urbanization by the population density per square kilometer, which we derived using the census values for total population and area of the electoral district.

Forth, we control for the percentage of citizens who are not born in the country. We expect those individuals who are born in the country of current residence (i.e. those born in Canada) to have a stronger attachment to "their" country than Canadians who came to Canada as immigrants. Native-born Canadians are more familiar with the political institutions and parties in their country; they have become politically socialized in their home country, and they have developed partisan attachments, all of which should contribute to higher turnout (Xu 2005). However, due to data unavailability on the percentage of naturalized citizens, we have to employ a suboptimal proxy variable for the percentage of naturalized citizens, namely the percentage of the population within any district that have not been Canadian citizens from birth. For sure, this includes naturalized citizens in the majority, but also permanent residents and individuals residing in Canada on a visa. Ideally, we would have liked to exclude the latter two categories, as they are ineligible to vote, but this is not possible with the data we have. We nevertheless assume that our proxy provides a somewhat valid operationalization measuring the influence of the proportion of non-Canadians by birth in a district on turnout.

Fifth, we control for the average number of polling stations per square kilometer in each district. The idea is that the closer the polling station is to somebody's home the quicker and less costly voting should be. In contrast, if voters have to drive several kilometers, or even tens of kilometers to get to their station, voting becomes more costly in terms of both time and money, and thus turnout should be lower (Aldrich 1993; Fedderson 2004). We calculated the average number of polling stations by dividing the absolute number of polling stations per district (provided in the Elections Canada data) by the size of the district measured in terms of square kilometers (as reported in the census data).

The sixth control variable is the competitiveness of the race. Following rational choice theory, we assume that the more competitive the electoral race is, the higher the turnout should be (Grofman et al. 1998). A competitive race increases every voter's chance that her vote will be 
decisive. Competitive races also trigger more campaign activity and increased media attention for the local race; both of which should also increase turnout (Cancela and Geys 2016). We measure competitive races as it is standard in the literature by the gap in votes between the winner and the runner-up of in the district.

Finally, we control for those districts that are located in Canada's north. In more detail, we identify, via a dummy variable, all 14 ridings whose territory fall within the 'Northern' or 'Northern Transition Zones', as defined by Statistics Canada (2006). ${ }^{13}$ These districts are generally large, sparsely populated and can experience extreme weather conditions, all of which can have an influence on turnout.

\section{Statistical Procedures}

Our data capture the population of electoral districts for our five elections. We use these data for the following types of analyses: first, we use the raw data and present some bivariate analyses (i.e. scatterplots) between either of our two weather proxies and district level turnout, respectively. Second, we present 3 pooled models. On the left-hand side is the dependent variable, district level turnout. On the right-hand side are the two independent variables; the precipitation per day measured in millimeters, and the daily average temperature, as well as the control variables. Our main model is a unit fixed effects model. This model is the most conservative model we could choose as it controls for other non-observed district-level characteristics (Allison 2009). It gauges if year-to-year weather changes within a district change electoral turnout. As robustness checks, we run the same model as a panel random effects model and a generalised least squares (GLS) model. To account for the fact that overall turnout and district level turnout differed in the 5 elections we cover, we include election dummies for the 2006, 2008, 2011 and 2015 general elections. The 2004 elections serve as the reference category in our three main models.

\section{Results}

The bivariate scatterplots mainly confirm our initial hypotheses; that is Figures 1 and 2 generally confirm (1) that more precipitation leads to lower turnout and (2) higher temperatures lead to higher turnout. ${ }^{14}$ In Figure 1, which gauges the influence between precipitation and turnout, all scatterplots show a flat or robust negative fitted line, confirming the notion that if it rains, some voters might prefer to stay at home rather than casting their ballot. Substantively, the scatterplots display a 0 to 5 percentage points' difference in turnout between district where it does not rain and districts where it rains a lot during Election Day (i.e. 15 millimeters of rainfall and more).

When it comes to temperature, our assumption that higher temperatures trigger higher turnout is confirmed in 3 out of the 5 scatterplots (figure 2). Except for the 2006 winter election,

\footnotetext{
${ }^{13}$ We we exclude the three districts of Canada's artic territories due to their size, extreme weather, low population and incredibly different social and political realities from the rest of Canada.

${ }^{14}$ Because of the different seasons during which our 5 elections took place, it is impossible to create one graph displaying the influence of temperature or precipitation on turnout.
} 
where higher temperatures led to fewer individuals casting their ballot and the 2015 election, where higher temperatures seem to have no impact on electoral participation, the remaining three elections show a solid relationship between warmer temperatures and higher turnout. This relationship seems particularly strong for the 2008 fall election. As such, the third scatterplot highlights that turnout was approximately 5 percentage points higher in districts with an average temperature between 15 and 20 degrees Celsius, as compared to districts with an average temperature between 0 and 5 degrees. In 2004, and 2011, the relationship was a bit less strong, but still in the vicinity of 2 to 3 percentage points between cold districts and warm districts.

Figure 1: Precipitation and turnout for the June 28, 2004, the January 23, 2006, the October 14, 2008, the May 2, 2011 and October 19, 2015 elections, respectively)

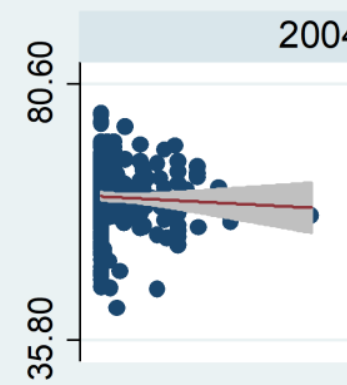

2011

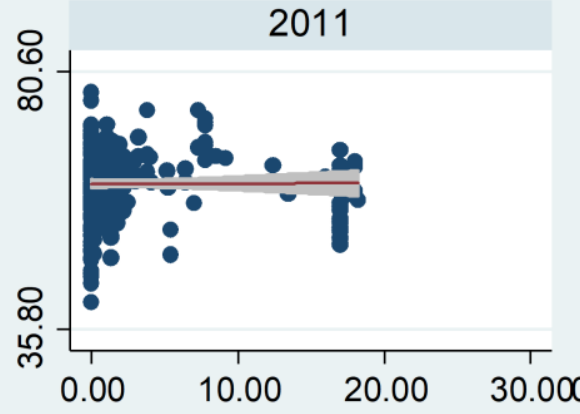

Total precipitation in $\mathrm{mm}$

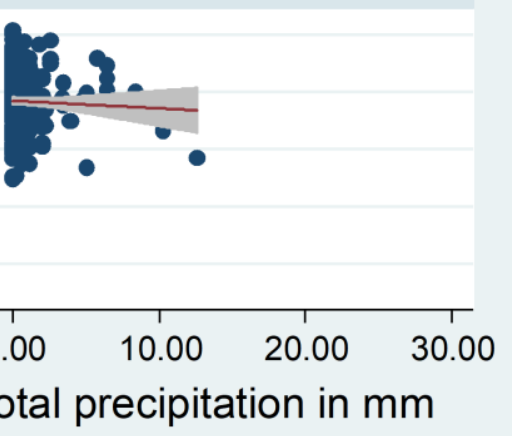

\section{Turnout \\ Fitted values}

$95 \% \mathrm{Cl}$

Graphs by year

The main exception of our general pattern is the 2006 winter general election. These elections reveal an opposite than expected relationship; in this January election, turnout was significantly higher in "cold" districts, where the average daily temperature was in the vicinity of -10 or -15 Celsius, than it was in less cold districts, with a temperature between 0 and 5 degrees Celsius. How can this rather unexpected finding be explained? Wouldn't it be logical that voters turn out more in relative warm temperatures (for winter) of around 0 or 5 degrees Celsius than in relatively cold weather with average temperatures of -10 or -15 degrees Celsius? Possibly, this 
relationship could be explained by the distribution of precipitation on Election Day. In other words, the warmer districts might have been the ones where it has rained or snowed a lot. To examine this possibility, we first run a correlation analysis; the Pearson correlation coefficient is .41 , indicating some medium-strong association between warmer weather and more precipitation. We examine this interaction effect below in more detail, by displaying a separate OLS model for 2006 with the addition of an interaction variable between the two weather proxies (see model 4). Because the winter elections of 2006 do not fit the general pattern, we also run models 1 to 3 excluding these elections (see models 5 to 7 ).

Figure 2 Scatterplot: Mean temperature on turnout for the June 28, 2004, the January 23, 2006, the October 14, 2008, the May 2, 2011 and October 19, 2015 elections, respectively.

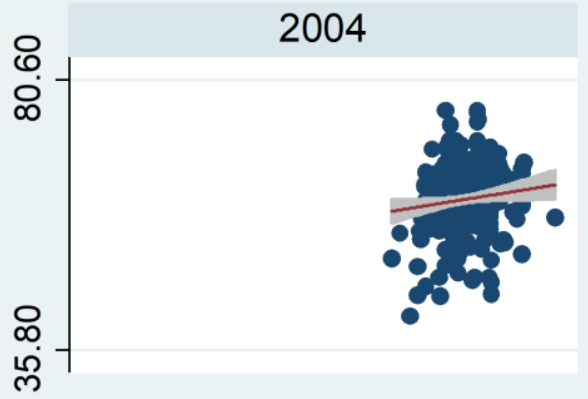

2006 2008

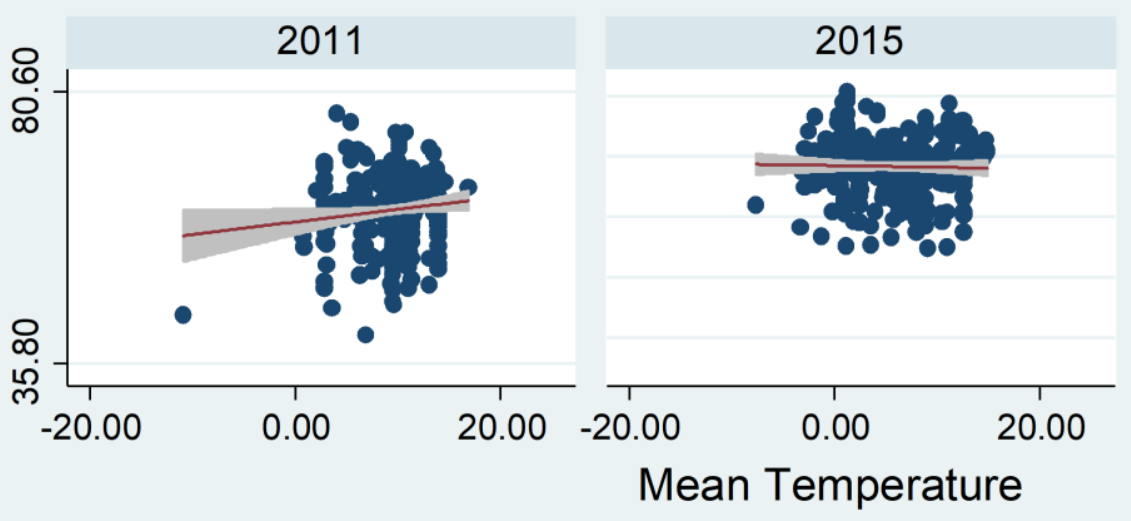

Turnout

$95 \% \mathrm{Cl}$

Fitted values

Graphs by year 
Our main regression models confirm the nuance from our bivariate analysis with the raw data. Models 1 to 3 indicate that precipitation moderately decreases turnout. In more detail, the three equations predict that per every millimeter of rain- or snowfall decreases turnout by approximately .1 points. In other words, 10 millimeters of precipitation decreases electoral participation by 1 percentage point. When it comes to temperature, Models 1 to 3 illustrate that for every degree the temperature gets warmer, turnout increases by .05 to .07 percentage points. In other words, a ten-degree temperature increase triggers approximately a half percentage point increase in participation rates. However, if we exclude the 2006 winter elections, the substantive influence of the variable temperature is more than twice as high as in our main equations. In other words, our additional regression models (see models 5 to 7), which exclude the winter 2006 elections predict that turnout increases at least .15 points for every degree Celsius the temperature is warmer. In other words, the models predict a 1.5 percentage point increase in turnout for a 10 degree increase in temperature.

Table 1: Multiple regression models measuring the influence of precipitation/temperature on turnout

\begin{tabular}{|c|c|c|c|c|}
\hline & $\begin{array}{l}\text { Model 1: Fixed } \\
\text { effects }\end{array}$ & $\begin{array}{l}\text { Model 2: Random } \\
\text { effects }\end{array}$ & Model 3: GLS & $\begin{array}{l}\text { Model 4: interactive (OLS with } \\
\text { Huber White standard errors) }\end{array}$ \\
\hline Average Temperature & $.074 * * *(.015)$ & $.070 * * *(.015)$ & $.052 *(.028)$ & $-.104 * *(.043)$ \\
\hline Total Precipitation & $-.113 * * *(.020)$ & $-.108 * * *(.020)$ & $-.082 * *(.037)$ & $-.125 * *(.079)$ \\
\hline Temperature*Precipitation & & & & $.036 * *(.019)^{15}$ \\
\hline Median district level age & $-.0000005(.00001)$ & $-.0000006(.00001)$ & $-.00003(.00003)$ & $.541 * * *(.082)$ \\
\hline $\begin{array}{l}\text { Median district level } \\
\text { income }\end{array}$ & $.0004 * * *(.00005)$ & $.0004 * * *(.00003)$ & $\begin{array}{l}.0005 * * * \\
(.00002)\end{array}$ & $.0007 * * *(.00006)$ \\
\hline Population density & $.0003(.0005)$ & $.00005(.0004)$ & $-.0007(.0005)$ & $.001(.001)$ \\
\hline $\begin{array}{l}\text { Average number of voting } \\
\text { stations per square } \\
\text { kilometer }\end{array}$ & $.023(.185)$ & $.118(.017)$ & $.455 *(.238)$ & $-.614(.526)$ \\
\hline $\begin{array}{l}\text { Percent immigrants per } \\
\text { district }\end{array}$ & $-.106 * * *(.039)$ & $-.125 * * *(.014)$ & $-.120 * * *(.010)$ & $-.067 * *(.017)$ \\
\hline Margin of Victory & $-.015 * * *(.005)$ & $-.024 * * *(.005)$ & $-.071 * * *(.007)$ & $-.048 * * *(.013)$ \\
\hline North & $-1.61(2.27)$ & $-.199(1.59)$ & $.318(1.23)$ & $-1.38(1.27)$ \\
\hline 2006 & $5.38 * * *(.370)$ & $5.29 * * *(.370)$ & $4.90 * * *(.691)$ & \\
\hline 2008 & $-1.45 * * *(.197)$ & $-1.47 * * *(.198)$ & $-1.47(.387)$ & \\
\hline 2011 & $-.705 * *(.286)$ & $-.812 * * *(.246)$ & $-1.13 * * *(.415)$ & \\
\hline 2015 & $6.34 * * *(.316)$ & $6.16(.281)$ & $.5 .65(.469)$ & \\
\hline Constant & $50.88 * * *(1.46)$ & $50.91(.949)$ & $51.32 * * *(.822)$ & $25.95 * * *(4.50)$ \\
\hline $\mathbf{R}^{2}$ & .51 & .53 & & .51 \\
\hline Log Likelihood & & & -4172.33 & \\
\hline Number of Observations & 1463 & 1463 & 1463 & 289 \\
\hline Number of Groups & 339 & 339 & 339 & 289 \\
\hline
\end{tabular}
Notes: Standard errors in parentheses. Significance: $* p<.1 ; * * p<.05 ; * * * p<.01$ (two-tailed).

${ }^{15}$ The estimate of .036 in model 4 is the effect of the product of temperature and precipitation (i.e., interaction effect). To interpret the interaction effect, we have to interpret the effect of temperature, precipitation and the interaction. 
Model 4 confirms that the 2006 winter election reveals a specific pattern confirming the bivariate finding that higher temperatures decrease turnout for this particular election. The same applies to high precipitation. In particular, in areas with relatively warm winter temperatures and a lot of precipitation turnout is higher. We can only speculate about the rather counterintuitive findings for the winter 2006 elections. Though the higher turnout could be an anomaly, it may still be explained in terms of opportunity costs. In those areas with no precipitation, the temperature was colder than in areas with precipitation, but still unseasonably warm for January; $5^{\circ} \mathrm{C}$ is essentially spring weather for most of Canada, and $-10^{\circ} \mathrm{C}$ a mild winter day. These rather pleasant temperatures in combination with sunshine might have made enjoying outdoor activities more enticing than voting for some citizens. Conversely, the presence of precipitation may negate the desire to enjoy the warm weather, hence the combination between warm weather and precipitation might have "decreased" the opportunity costs, leading more citizens to turn out. A similar logic is used by Lind (2014) to explain the positive relationship between rain and turnout in Norwegian municipal elections, although with no analysis of the role of temperature.

Table 2: Multiple regression models measuring the influence of precipitation and the temperature on turnout excluding the year 2006

\begin{tabular}{llll}
\hline & Model 5: Fixed effects & Model 6: Random effects & Model 7: GLS \\
\hline Average Temperature & $.169 * *(.020)$ & $.164 * * *(.020)$ & $.150 * * *(.037)$ \\
\hline Total Precipitation & $-.084 * *(.023))$ & $-.076 * *(.023)$ & $-.42 *(.043)$ \\
\hline Median district level age & $-0000007(.00001)$ & $-.0000008(.00002)$ & $-.00003(.00003)$ \\
\hline Median district level income & $.0004 * * *(.000005)$ & $.0004 * * *(.00003)$ & $.0005 * * *(.00002)$ \\
\hline Population density & $.0004(.0005)$ & $.0001(.0005)$ & $-.0008(.0006)$ \\
\hline Average number of voting & $-.021(.207)$ & $.111(.192)$ & $.515 *(.266)$ \\
stations per square kilometer & & & $-.134 * * *(.011)$ \\
\hline Percent immigrants per district & $-.146 * * *(.041)$ & $-.142 * * *(.015)$ & $.418(1.37)$ \\
\hline North & $-.727(2.31)$ & $.081(1.62)$ & $-.950 * *(.416)$ \\
\hline $\mathbf{2 0 0 8}$ & $-.937 * *(.209)$ & $-.965 * * *(.210)$ & $-.445(.451)$ \\
\hline $\mathbf{2 0 1 1}$ & $-.036(.314)$ & $-.171(.266)$ & $6.85(.551)$ \\
\hline $\mathbf{2 0 1 5}$ & $7.46 * *(.367)$ & $7.27(.324)$ & $50.57 * * *(.940)$ \\
\hline Constant & $50.39 * * *(1.54)$ & $50.02 * * *(.987)$ & .54 \\
\hline R & .53 & & -3369.13 \\
\hline Log Likelihood & & 1774 & 1774 \\
\hline Number of Observations & 1174 & 338 & 338
\end{tabular}

Notes: Standard errors in parentheses. Significance: $* p<.1 ; * * p<.05 ; * * * p<.01$ (two-tailed).

\section{Conclusion}

This article pushes our understanding of the weather-turnout nexus forward. As the first study that looks at the association between the weather and turnout in all four seasons we make important observations. First, we confirm most prior research that highlights that precipitation decreases turnout, whereas higher temperatures increase turnout. This association seems to hold 
reasonably well for spring, summer and fall elections. Substantively, we find that for every millimeter of precipitation turnout decreases by .1 percentage points. The relationship for temperature is of a somewhat smaller magnitude; that is for every degree the temperature increases turnout increases by approximately .7 degrees. These impacts are slightly larger in comparison to most other studies, hinting that rain/snowfall and the daily temperature on Election Day could explain fluctuations in turnout of several percentage points. ${ }^{16}$

Second, our results also indicate that for the winter elections, this general pattern might not hold. In particular, we find that colder temperatures trigger higher turnout; this finding applies, in particular, to regions with no precipitation. In contrast, in districts with high precipitation, the combination between mild winter temperatures and high amounts of precipitation triggers higher turnout. Hence, the winter elections do not confirm the general relationship. The costs and opportunity costs associated with winter voting might be more complex and require further inquiry not only in Canada, but in other countries and regions, as well.

For policy, this study allows for the tentative conclusion that scheduling elections during more pleasant weather could moderately increase turnout. If it is warm and does not rain on Election Day, more individuals will turn out as compared to a relatively cold and rainy day. Nevertheless, addressing the effects of the weather alone will not dramatically change turnout. Rather, to reach turnout figures achieved in the 1950s and 1960s in Canada and elsewhere in Western countries, it is necessary that citizens achieve equally high amounts of political interest and knowledge than citizens had decades ago. On the institutional side, the only measure that would significantly increase turnout would be the implementation of mandatory compulsory voting, which, in turn, could reveal other ethical considerations.

A possible avenue for future research is to further investigate which Canadian voters are deterred by inclement weather. Other studies have found patterns in partisan affiliation, such as US Republicans being less affected, as well as that those with low senses of civic duty (Knack 1994; Gomez 2007). Theoretically, we could also expect that elderly voters with decreased mobility may worry about slipping in ice or rain.

${ }^{16}$ Unfortunately, we could not consider early voting, which ranged from 5.5 in 2004 to 20.5 percent in 2015. 


\section{References:}

Aldrich JH (1993) Rational choice and turnout. American journal of political science 246-278 Allison PD (2009) Fixed effects regression models. SAGE publications

Arnold F (Forthcoming) Turnout and Closeness: Evidence from 60 Years of Bavarian Mayoral Elections. Scand J of Economics. doi: 10.1111/sjoe.12241

Arnold F, Freier R (2016) Only conservatives are voting in the rain: Evidence from German local and state elections. Electoral Studies 41:216-221

Artés J (2014) The rain in Spain: Turnout and partisan voting in Spanish elections. European Journal of Political Economy 34:126-141

Bassi A (2013) Weather, Mood, and Voting: An Experimental Analysis of the Effect of Weather Beyond Turnout. Social Science Research Network, Rochester, NY

Ben Lakhdar C, Dubois E (2006) Climate and Electoral Turnout in France. French Politics 4:137-157 . doi: http://dx.doi.org/10.1057/palgrave.fp.8200100

Blais A (2006) What affects voter turnout? Annu Rev Polit Sci 9:111-125

Cancela J, Geys B (2016) Explaining voter turnout: A meta-analysis of national and subnational elections. Electoral Studies 42:264-275

Corvalan A, Cox P (2013) Class-Biased Electoral Participation: The Youth Vote in Chile. Latin American Politics and Society 55:47-68

Dubois E, Lakhdar CB (2007) More on the Seasonal Determinants of Turnout: Holidays and French Presidential Elections. French Politics; Basingstoke 5:144-159 . doi: 10.1057/palgrave.fp.8200123

Eisinga R, Grotenhuis M, Pelzer B (2012a) Weather conditions and political party vote share in Dutch national parliament elections, 1971-2010. International Journal of Biometeorology 56:1161-1165 . doi: 10.1007/s00484-011-0504-8

Eisinga R, Grotenhuis MT, Pelzer B (2012b) Weather conditions and voter turnout in Dutch national parliament elections, 1971-2010. Int J Biometeorol 56:783-786 . doi: 10.1007/s00484-011-0477-7

Elections Canada (2006) Report of the Chief Electoral Officer of Canada on the 39th General Election of January 23, 2006

Elections Canada (2017) Elections Canada's Official Reports — Official Voting Results. In: Elections Canada. http://www.elections.ca/content.aspx?section=res\&dir=rep/off\&document=index\&lang=e \#officialvoting. Accessed 16 May 2017

Feddersen TJ (2004) Rational choice theory and the paradox of not voting. The Journal of Economic Perspectives 18:99-112

Fraga BL, Hersh E (2010) Voting costs and voter turnout in competitive elections

Franklin MN (2004) Voter turnout and the dynamics of electoral competition in established democracies since 1945. Cambridge University Press

Funke A (2017) Pundits' Guide to Canadian Elections. https://www.punditsguide.ca/ 
Gallego A (2010) Understanding unequal turnout: Education and voting in comparative perspective. Electoral Studies 29:239-248

Gatrell JD, Bierly GD (2013) Weather and Voter Turnout: Kentucky Primary and General Elections, 1990-2000. Southeastern Geographer 42:114-134 . doi:

$10.1353 /$ sgo. 2002.0007

Geys B (2006) Explaining voter turnout: A review of aggregate-level research. Electoral studies 25:637-663

Gomez BT, Hansford TG, Krause GA (2007) The Republicans Should Pray for Rain: Weather, Turnout, and Voting in U.S. Presidential Elections. The Journal of Politics 69:649-663 . doi: 10.1111/j.1468-2508.2007.00565.x

Grofman B, Collet C, Griffin R (1998) Analyzing the turnout-competition link with aggregate cross-sectional data. Public Choice 95:233-246

Knack S (1994) Does rain help the Republicans? Theory and evidence on turnout and the vote. Public Choice 79:187-209 . doi: 10.1007/BF01047926

LeDuc L, Pammett JH (2006) Voter Turnout in 2006: More Than Just the Weather. In: Pammett JH, Dornan C (eds) The Canadian federal election of 2006. Dundurn Press, Toronto ON, pp 305-326

Lind JT (2014) Rainy Day Politics -- An Instrumental Variables Approach to the Effect of Parties on Political Outcomes. Social Science Research Network, Rochester, NY

Ludlum D (1989) The Weather Factor. American Meteorological Society, Boston

Matsusaka JG, Palda F (1999) Voter turnout: How much can we explain? Public choice 98:431446

Melo DF, Stockemer D (2014) Age and political participation in Germany, France and the UK: A comparative analysis. Comparative European Politics 12:33-53

Merrifield J (1993) The institutional and political factors that influence voter turnout. Public Choice 77:657-667 . doi: 10.1007/BF01047865

Nova Scotia House of Assembly (2009) Report of the Select Committee on Participation in the Democratic Process, 2009, Draft ed. Nova Scotia Legislative Assembly, Halifax, N.S.

Persson M, Sundell A, Öhrvall R (2014) Does Election Day weather affect voter turnout? Evidence from Swedish elections. Electoral Studies 33:335-342 . doi:

10.1016/j.electstud.2013.07.021

Rallings C, Thrasher M, Borisyuk G (2003) Seasonal factors, voter fatigue and the costs of voting. Electoral Studies 22:65-79 . doi: 10.1016/S0261-3794(01)00047-6

Statistics Canada (2006) What is north? In: Canada Year Book 2006. Statistics Canada, Ottawa Statistics Canada (2008) Federal Electoral District (FED) Profile, 2006 Census. Ottawa Statistics Canada (2012) Reasons for not voting. http:/www.statcan.gc.ca/pub/11-402x/2012000/chap/sc/sc01-eng.htm. Accessed 15 Apr 2017

Statistics Canada (2013a) 2011 Census Profile. Ottawa

Statistics Canada (2013b) 2011 National Household Survey. Ottawa 
Stockemer D (2017) What affects voter turnout? A review article/meta-analysis of aggregate research. Government and Opposition 52:698-722

Stockemer D, LaMontagne B, Scruggs L (2013) Bribes and ballots: The impact of corruption on voter turnout in democracies. International Political Science Review 34:74-90

Studlar DT (2001) Canadian Exceptionalism: Explaining Differences over Time in Provincial and Federal Voter Turnout. Canadian Journal of Political Science 34:299-319

Verba S, Schlozman KL, Brady HE (1995) Voice and equality: Civic voluntarism in American politics. Harvard University Press

$\mathrm{Xu} \mathrm{J}$ (2005) Why do minorities participate less? The effects of immigration, education, and electoral process on Asian American voter registration and turnout. Social science research 34:682-702 